\title{
Therapeutic Patient Education for Adrenal Insufficiency under COVID-19 Pandemic Conditions
}

\author{
Authors \\ Tina Kienitz ${ }^{1}$, Stefanie Hahner ${ }^{2}$, Stephanie Burger-Stritt ${ }^{2}$, Marcus Quinkler ${ }^{1}$
}

\author{
Affiliations \\ 1 Endocrinology in Charlottenburg, Berlin, Germany \\ 2 Endocrinology and Diabetes Unit, Department of Medicine \\ I, University Hospital Wuerzburg, Wuerzburg, Germany
}

\section{Key words}

adrenal crisis, hydrocortisone, secondary adrenal insufficiency, emergency card

received 27.03.2020

revised 25.06.2020

accepted 08.07.2020

published online $\quad 06.08 .2020$

\section{Bibliography}

Exp Clin Endocrinol Diabetes 2021; 129: 241-249

DOI 10.1055/a-1217-7208

ISSN $0947-7349$

(C) 2020. Thieme. All rights reserved.

Georg Thieme Verlag KG, Rüdigerstraße 14,

70469 Stuttgart, Germany

\section{Correspondence}

Marcus Quinkler, MD

Endocrinology in Charlottenburg

Stuttgarter Platz 1

D 10627

Berlin

Germany

Tel.: +4930 2132004, Fax: +49302132005

marcusquinkler@t-online.de

\section{ABSTRACT}

Adrenal insufficiency ( $\mathrm{Al}$ ) requires life-long treatment with glucocorticoid replacement therapy. Over- or under-substitution carries the risk of increased morbidity in the form of side effects or adrenal crises. Glucocorticoid replacement therapy needs to be flexible with dose adaptation in special situations. This could not be managed by medical personnel on a daily basis, but requires an educated patient who has a good knowledge of the disease, understands his medical therapy and is able to perform situational dose adaptation. The rarity of the disease in combination with the need to respond to stressful situations with rapid glucocorticoid dose adjustment underlines that a well-trained patient is crucial for optimal management of the disease. In this literature review we provide background information further clarifying the need of education in patients with $\mathrm{Al}$ including the current shortcomings of medical therapy and of the treatment of patients with Al. We outline the aims of therapeutic patient education, present the concept of structured patient education in Germany, and discuss available results of patient group education programs. Furthermore, we propose strategies how therapeutic patient education for adrenal insufficiency can be organized under COVID-19 pandemic conditions.

\section{Background}

The long-term management of patients with adrenal insufficiency (AI) is a challenge in several respects. Increased morbidity and mortality and reduced quality of life together with impairments in work-life and leisure activities have been documented. With normal function, the adrenal gland is a very dynamic organ that responds quickly to an increased need for corticosteroids. Sufficient supply of glucocorticoids to the body is vital. It is also highly relevant for the management of everyday tasks and the maintenance of general performance. Over- or under-substitution carries the risk of increased morbidity in the form of side effects or adrenal crises. While other diseases are treated with constant medication, Al often requires fast action with situational dose adaptation. Re- duced quality of life may in part be optimized by an improved dose regimen, but also an improved knowledge of the disease and of possible options for action by the patient. The rarity of the disease in combination with the need to respond to stressful situations with rapid glucocorticoid dose adjustment underlines that a well-educated patient is crucial for optimal management of the disease.

Patient's education should fulfill several aims: a) to provide a better understanding of the illness and to increase quality of life; b) to reduce morbidities and increase long-term outcome through optimized dose adaptation and avoidance of over- or under-substitution; c) to reduce mortality by preventing adrenal crisis (AC).

In the following paragraph we provide background information further clarifying the need of education in patients with Al. 


\section{Mortality}

Recent studies revealed increased mortality in chronic Al patients [1-5]. A study analyzing the National Swedish Hospital and Cause of Death Registry showed an increased mortality in patients with Addison's disease (2.2-fold for men and 2.9-fold for women) compared to normative data [6]. Especially the mortality due to infectious diseases was greatly increased (6.6-fold in men and 5.6-fold in women) [6]. This data is endorsed by a study from the Netherlands showing an increased incidence of infectious disease in Addison's disease [7].

But also in patients with secondary Al the standardized mortality ratio is increased up to 3.5-fold in men and 4.5-fold in women, as analyzed in a review by Sherlock et al. [3]. A Swedish study with 755 patients with secondary Al described an even higher standard mortality ratio for death from infectious disease of 8.9-fold [2]. This data suggests that patients with chronic Al are particularly threatened by infectious disease and that AC substantially contributes to the increased mortality in secondary AI. The most common form of $\mathrm{Al}$ is iatrogenic $\mathrm{Al}$ due to immuno-suppressive, or -modulatory glucocorticoid doses, or as side effect of a checkpoint-inhibition therapy. The underdiagnosis and underrecording of adrenal dysfunction in those patients is common in clinical practice and leads to a high mortality [8].

Several studies in secondary Al indicate that high hydrocortisone doses as glucocorticoid replacement therapy are associated with an increased mortality. This was demonstrated in 178 acromegalic patients with secondary AI [9], where daily hydrocortisone doses above $25 \mathrm{mg}$ significantly increased mortality. This finding was supported by an analysis in 105 patients with non-secreting pituitary adenoma and secondary Al [10] showing a 4-fold increase in total mortality for daily hydrocortisone doses above $30 \mathrm{mg}$. It is assumed that increased daily hydrocortisone doses lead to higher cardiovascular risk factors, thus resulting in higher death rates from vascular disorders in patients with hypopituitarism [11]. A recent study from England, Netherlands and Denmark confirmed this finding demonstrating that patients taking a glucocorticoid treatment had a 2 -fold increased standard mortality ratio compared to the general population, whereas patients without daily glucocorticoids were not different to the general population [12]. Furthermore, data from the European Adrenal Insufficiency Registry showed that especially older, male patients with secondary Al and with hypertension and diabetes mellitus receiving higher hydrocortisone doses had a higher mortality risk [13]. Even daily doses of $30 \mathrm{mg}$ of daily hydrocortisone showed a much more unfavorable blood pressure profile compared to doses of 15 or $20 \mathrm{mg}$ hydrocortisone potentially contributing to the observed excess mortality $[14,15]$.

\section{Adrenal crisis}

Adrenal crisis (AC) is a life-threatening emergency that may occur in patients with chronic $\mathrm{Al}$ and is in part responsible for the increased mortality [16-20]. A clear definition of AC is difficult and varies among studies, contributing to varying numbers and causes of AC. Allolio defined AC [21] as profound impairment of general health and at least two of the following conditions: hypotension (systolic blood pressure $<100 \mathrm{mmHg}$ ), nausea or vomiting, severe fatigue, hyponatremia, hypoglycemia and hyperkalemia, triggering subsequent parenteral glucocorticoid administration. Even if
$A C$ is recognized and treated accordingly it is associated with a high mortality of $6.3 \%$ [22] suggesting that if not recognized and correctly treated, it is responsible for a large percentage of deaths among Al patients [2, 5]. In a Norwegian analysis, "adrenal failure" was the second most frequent cause of death (15\%) in patients with Addison's disease [1].

Precipitating factors for $A C$ are stressful conditions leading to an increased glucocorticoid demand like infectious disease (especially gastroenteritis and other infectious diseases), trauma, surgery, but also psychological distress (mental or emotional stress), strenuous physical activity, as well as changes in glucocorticoid replacement therapy $[7,17,18,22]$. Thus, it is of high importance that patients with $\mathrm{Al}$ adjust their glucocorticoid dose under stressful conditions to prevent AC.

In a retrospective study from Germany the frequency of $A C$ was measured with 6.6 crises per 100 patient years in primary Al and 5.8 crises per 100 patient years in secondary Al [18]. Retrospective data from the Netherlands revealed similar data (5.2 crises in primary Al and 3.6 crises in secondary Al per 100 patient years) [7]. Data from the UK Addison disease self-help group showed a higher $A C$ rate with 8 crises per 100 patient years in primary Al [17]. The only prospective $A C$ study revealed an even higher frequency with $64 \mathrm{ACs}$ in 767.5 patient years resulting in 8.3 crises per 100 patient years [22].

AC requires immediate substitution of $100 \mathrm{mg}$ hydrocortisone as intravenous bolus, followed by $100-300 \mathrm{mg}$ hydrocortisone as a continuous infusion over $24 \mathrm{~h}[21,23]$. Furthermore, adequate fluid replacement with physiological saline solution ( $\mathrm{NaCl} 0.9 \%$ intravenously, initially $1 \mathrm{~L} / \mathrm{h}$ ) under continuous cardiac monitoring is necessary. If the reason for the patient's impaired condition is Al, improvement in response to glucocorticoids is usually seen within $12 \mathrm{~h}$. Precipitating factors of AC such as infections should be treated in addition (e.g. antibiotics, low-dose heparin treatment, prophylaxis of stress ulcer) [23]. Depending on the clinical condition of the patient, the steroid dosage may be reduced the following day and then tapered to the patient's individual daily dose.

It is worrisome that even in well-treated Al patients AC occurs. Retrospective data demonstrate that about half of the patients with chronic Al have already experienced at least one AC since diagnosis $[7,17,18]$. Hahner et al. showed in the prospective study that patients with a previous $A C$ were at higher risk of crisis (odds ratio 2.85) [22]. Of note, most of these patients with history of AC were more proactive in adaptation of their glucocorticoid replacement dose, e.g. in case of fever, indicating good educational status but increased vulnerability towards AC [22]. For several patients of this study, the first crisis was lethal. Additional risk factors identified were female sex, primary Al, diabetes insipidus and concomitant non-endocrine disease $[7,17,18]$.

\section{Current concepts of glucocorticoid replacement doses and adjustments}

The challenge of management is to tailor the glucocorticoid replacement therapy to the needs of each patient [24]: the daily maintenance dose, the daily dose/ exposure of cortisol required to mimic normal physiology, and the need for extra cortisol during an intercurrent illness or non-illness-related events, such as exercise, in order to prevent AC. 
Hydrocortisone is the most commonly used glucocorticoid for Al therapy [25] and is administered between twice and four times daily with the highest dose in the morning [26]. The physiological daily cortisol production rate is $5-10 \mathrm{mg} / \mathrm{m}^{2}$ body surface [27], suggesting daily doses between 10 and $25 \mathrm{mg}$ hydrocortisone in Al patients. Doses should be customized on an individual basis, may be guided by weight-related regimens [28] and concomitant medications need to be considered [24]. This individual tailoring is expressed by the recently presented 25 different regimens used to deliver a daily hydrocortisone dose of $20 \mathrm{mg}$ in Al patients [25].

However, current glucocorticoid replacement therapy in patients with Al does not mimic the exact physiological rhythm, e.g. the ultra-circadian rhythm. In addition, over-replacement of hydrocortisone may lead to increased mortality and increased cardiovascular morbidity $[9,10]$, whereas under-replacement can result in significant impairment of quality of life and could lead to lifethreatening $A C$ if the patient develops an intercurrent illness.

The physiological cortisol production in healthy individuals is highly variable during the day and further influenced by many factors that activate stress responses like physical activity, pain, infections, psychological stress, low blood glucose etc. Therefore, it is crucial in our current understanding that we use the lowest possible daily hydrocortisone dose to prevent cardiovascular and metabolic comorbidities. However, it is necessary to teach and instruct the patient to adapt doses in the case of an intercurrent illness or non-illness-related events.

In case of defined strong and prolonged physical activity (e.g. intensive fitness training or running for several hours) an additional hydrocortisone dose of $5-10 \mathrm{mg}$ is recommended. In contrast, short physical activity does not seem to require additional doses $[29,30]$. An additional dose of hydrocortisone might also be considered in situations of severe and prolonged psychological stress (e.g. death of a relative, acute depression) as such conditions have also been reported to cause AC [22]. Ideally the additional dose should be given well before - not at the time of - the expected stress, however this is often difficult to foresee. It is important to timely reduce the hydrocortisone dose back to the standard dose to avoid over-replacement. Short lasting stressors usually do not routinely require dose adaptation. In case of minor physical stress (infectious diseases with fever, stress, surgery under local anesthesia) or major and prolonged psychological stress, the daily hydrocortisone replacement dose should be doubled or tripled to approximately $40-50 \mathrm{mg} /$ day [31]. Under conditions of medium or major physical stress (trauma, surgery with general anesthesia, delivery) and in case of diarrhea/vomiting hydrocortisone needs to be substituted intravenously (100-250 mg/24h) [31].

All patients with $\mathrm{Al}$ should receive a national steroid emergency card [32], which gives information on the underlying cause, the current replacement regime, and the responsible endocrinologist. They should also be provided with the newly created European emergency card [33, 34]. In addition, some patients wear a MedicAlert bracelet, necklace, or anklet providing an emergency phone number to access the patient's clinical details.

Every Al patient should be equipped with a glucocorticoid emergency kit containing additional hydrocortisone tablets, rectal prednisolone suppositories (which are easily administered and useful for travels), and a hydrocortisone emergency kit (e.g. ampoule with $100 \mathrm{mg}$ hydrocortisone-21-hydrogensuccinate for intramuscular injection) including syringes. The prerequisite is that patients (together with relatives) are educated in self-administration of hydrocortisone as intramuscular injection in emergency situations.

\section{Current shortcomings}

National and the European emergency card are not distributed well enough. In a survey of patients with $\mathrm{Al}, 94 \%$ of respondents carried a national emergency card [18], but the card was not homogenous. $73 \%$ of the German endocrine centers hand out the emergency card of the German patients' self-help network (Netzwerk für Hypophysen- und Nebennierenerkrankungen e.V.), whereas $16 \%$ use emergency cards distributed from 4 different pharmaceutical companies, and $6 \%$ use self-made emergency cards [35]. These different national cards reduce the recognition value among emergency personnel and might lead to disbelief and ignorance among emergency staff regarding the patient's underlying illness. Furthermore, the National German Audit of Diagnosis, Treatment, and Teaching in Secondary Adrenal Insufficiency of 50 endocrine centers revealed that only $51 \%$ of the centers distribute the German version of the European emergency card [33, 34] to their patients, whereas $49 \%$ did not [35].

Medical personnel are frequently not reacting as recommended in emergency situations with Al patients. A retrospective study comparing reported time intervals with time targets recommended by an European expert panel revealed a delay of glucocorticoid administration by medical professionals in $46 \%$ of cases [36]. Only $54 \%$ of the patients received glucocorticoids parenterally within $30 \mathrm{~min}$ (with a range of 2-2400 $\mathrm{min}$ ) after presentation of the emergency card to the medical professional [36]. The European expert panel considered 30 min as time limit for "card-injectiontime" in case of an AC within the same trial [36]. A recent prospective evaluation of emergency management showed a large variability in emergency measures: the median time from showing the emergency card to a medical professional to parenteral glucocorticoid administration by a medical professional (card-injectiontime) was $60 \mathrm{~min}$ (5-360). Only $45 \%$ of the patients received glucocorticoids by a physician within $30 \mathrm{~min}$ [37]. One reason for this shortcoming might be insufficient knowledge of physicians of Al. Only less than $10 \%$ of interviewed physicians identified all situations requiring glucocorticoid adjustment correctly [38, 39]. Another reason might be the low recognition value of different emergency cards handed out to patients.

Patients are not equipped for emergency situations. Only $30 \%$ of Al patients possessed a glucocorticoid emergency kit. $10 \%$ reported that they had never increased their glucocorticoid dose [18]. The German national audit regarding SAI patients revealed that only $61 \%$ of the centers prescribe additional hydrocortisone tablets, only $59 \%$ prescribed prednisone/ prednisolone suppositories, $65 \%$ a $100 \mathrm{mg}$ hydrocortisone ampoule, $2 \%$ a $50 \mathrm{mg}$ prednisolone ampoule, $4 \%$ hydrocortisone suppositories, and $5 \%$ betamethasone liquid [35].

Patients are not educated well enough for emergency situations. Only a few patients were able to or knew how to self-inject, and most of them relied on medical personnel for emergency glucocorticoid replacement treatment [17]. In the German national 
audit $84 \%$ of the centers answered that they perform patient education, which was mostly done on an unstructured basis and took place during the short consulting time (average appointment time 5-15 min) [35]. Furthermore, in $47.8 \%$ of the centers patient education is done by the doctor, in $28.8 \%$ of the centers by the doctor's assistant, in $14.5 \%$ by a trained endocrine nurse, in $7.4 \%$ of the centers by a nurse or study nurse, and in $2.5 \%$ of centers by a diabetes nurse. Relatives are involved in patient education only in $52 \%$ of the centers [35]. Recent data from a prospective study showed that patients who performed a self-injection had an improved outcome: after initial parenteral (intramuscular or subcutaneous) glucocorticoid administration by patients or their relatives, significantly more patients were treated on an outpatient basis (62\%) compared to patients who did not self-inject (27\%), $(p=0.008)$ [37]. Two surveys from 2013 and 2017/18 in British patients revealed that within a 5-year interval more patients performed self-injection for treatment of emergency situations (16.7\% versus $24 \%$ ) [40].

The content of patient education is very heterogenous among centers. Among German endocrine centers there is a broad agreement on advices given to patients regarding behavior in conditions, such as diarrhea, fever of $38.5^{\circ} \mathrm{C}$ and light fever (flu) [35]. Howev$\mathrm{er}$, recommendations and patient education varied considerably regarding situations involving psychological stress, 60 min sport activity, common cold (without fever), coughing (without fever), or dental treatment [35].

Patients have concerns and fears regarding their illness and their therapy. Nonadherence has been recognized as a significant challenge by the World Health Organization suggesting that only $50 \%$ of patients with chronic conditions take their medications as recommended. In Al, $23 \%$ of patients report dissatisfaction with treatment, $38 \%$ find multiple daily dosing problematic, over $50 \%$ perceive that glucocorticoids interfere with life aspects such as work, travel or sex life, and many missed tablets or took them before sleep which resulted in fatigue or insomnia [41]. Recent data report poor adherence of Al patients [42] and reveal many concerns regarding patients' glucocorticoid replacement therapy and possible side events [43]. A study analyzing patient's diary data revealed that the perception of discomfort does not always seem to result in a glucocorticoid dose increase in $\mathrm{Al}$ patients, especially in situations indicating $\mathrm{Gl}$ infection. On the other hand, possible overdosing was seen in some patients [44].

\section{Aims of Patient Education}

All patients with $\mathrm{Al}$ must receive a structured crisis prevention education together with their partners or relatives and this should be given at the time of first diagnosis [31]. In addition, during each follow-up visit (ideally twice a year) the patient should be trained in recognizing typical stressful situations (fever, infection, stress, surgery or trauma) and symptoms of acute $\mathrm{Al}$, and instructed on glucocorticoid dose adjustment in these situations. Therefore, patient education is currently the most important measure for prevention of $A C$ [45]. It should be stressed that patient education is part of the endocrinologist's therapeutic responsibility.

We believe that it is necessary to implement a structured education and treatment program for patients with Al. Therefore, we recently started to develop and implement a structured patient education program in Germany [46]. This was initiated by nine tertiary endocrine centers across Germany and the section "Nebenniere, Steroide und Hypertonie" of the German Endocrine Society (DGE) by the end of 2014.

The aim is:

- to provide a homogeneous and structured patient education across Germany

- to impart knowledge to Al patients about their condition

- to encourage and enable patients to adjust their hydrocortisone medication in special situations, thereby regaining independence and improving their radius of action

- to empower patients to take care of themselves

- to provide a platform for exchange of experience between participating patients

- to train self-, respectively partner-injection of parenteral hydrocortisone in case of emergency

- to prevent adrenal crises.

Since then, on a yearly basis the section "Nebenniere, Steroide und Hypertonie" offers a 6-8 h certification course called "Structured patient education for patients with Al" to interested endocrine centers. For each center it is obligatory that an endocrinologist and an endocrine nurse/ endocrine assistant take part as tandem. The program includes the following topics: presentation of the project, data regarding quality of disease management in patients with $\mathrm{Al}$ (background and why we need a structured patient education program), results of the evaluation of the German structured patient education program, presentation of the patient education program (structure, content, messages, learning points, hand-on exercise: emergency injection) and an interactive group work. After successful participation in the certification course, the endocrine centers are qualified for the use of the patient education program. Standardized training materials (and the patient education program) are available to all qualified teaching teams via an internet-based platform (cloud). Starting from 8 centers in 2014, this patient education program has been provided to 77 endocrine centers by the end of 2018 with 186 medical personnel to educate Al patients in a standardized manner ( $>$ Fig. 1 ).

\section{Methods of Patient Education}

The program consists of multiple elements, topics and learning points to tailor the patient education individually to the needs of the patients attending the teaching. Patient education takes place in small groups of 3-5 patients with accompanying relatives or spouses and a length of 90-120 min. Patients receive general information on $\mathrm{Al}$, learn about signs and symptoms of hypocortisolism, steroid adjustment in special situations and in critical situations, and self-injection of parenteral hydrocortisone. The structured patient education program can be modified by adding additional 5-10 min modules with specific education topics in the event that patients are asking for a specific topic or the patient group consists of one specific patient group. These additional modules cover topics such as congenital adrenal hyperplasia, pregnancy, mineralocorticoid therapy in primary Al or patients on mitotane therapy. In addition, all required materials are provided to the pa- 


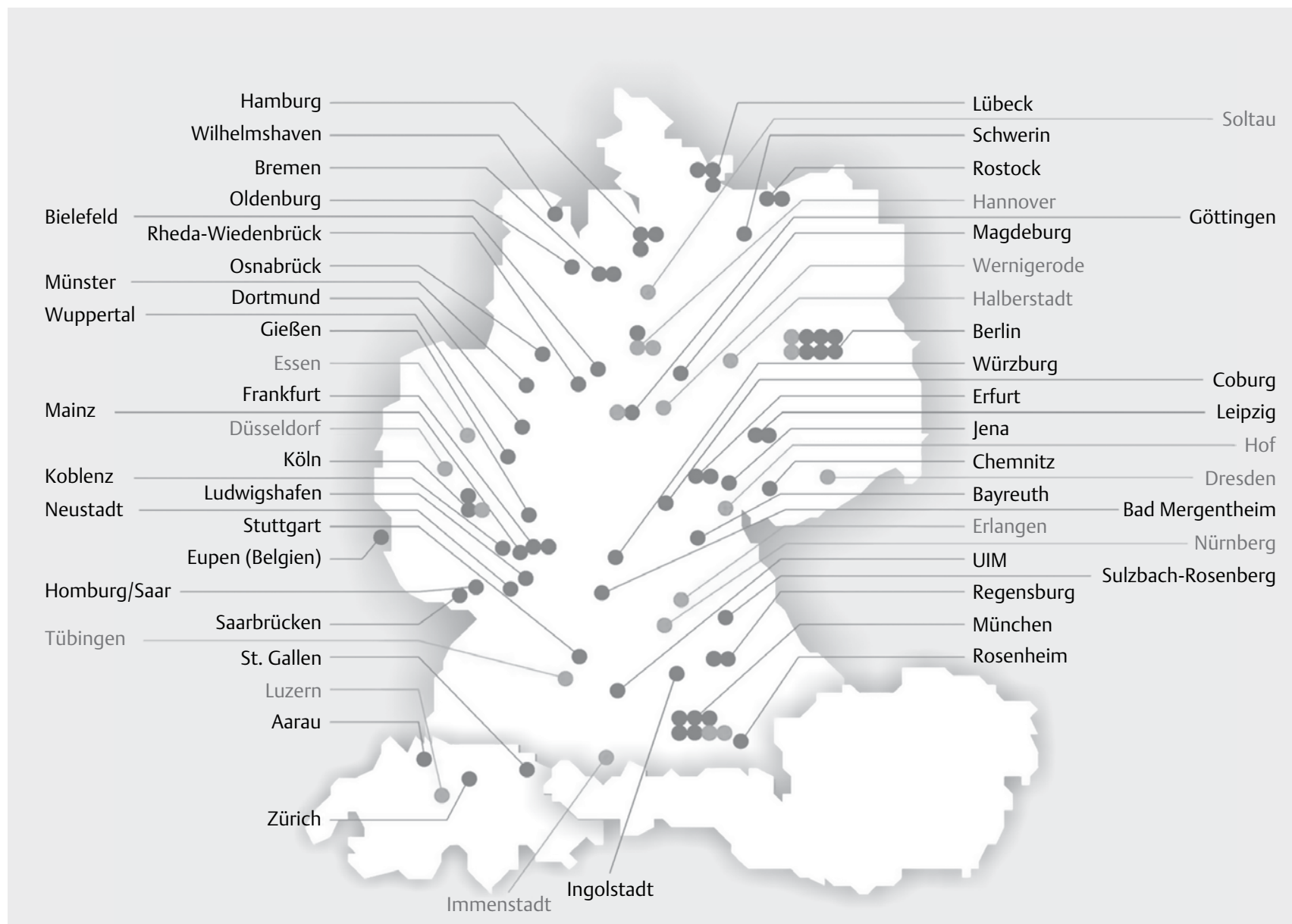

- Fig. 1 Endocrine centers in Germany and neighboring countries who were instructed with the structured patient education program of the section "Nebenniere, Steroide und Hypertonie" of the German Endocrine Society (DGE) by end of 2018, and who offer a standardized patient education program on a regular (black) or an irregular (light grey) basis (with friendly permission of Smadar Pahl, Oldenburg, Germany).

tients including the national emergency card, the European emergency card, the emergency kit, leaflets, etc.. Furthermore, we provide patients with information about useful web-pages in German, such as the patients' information page of the German Endocrine Society (https://www.endokrinologie.net/krankheiten-nebenniereninsuffizienz.php) and the Dutch AdrenalNET (https://adrenals. $\mathrm{eu} / \mathrm{de} /$ ). The latter offers short animation videos explaining $\mathrm{Al}$, handling of emergency situation and administration of the emergency injection, as well as an app for smartphones (https://adrenals.eu/ de/app/).

\section{Results of Patient Education}

A structured patient education program has been implemented in the Netherlands and proven to be beneficial especially regarding improved patients' knowledge about their disease, dose adaptation in situations of intercurrent illness and emergency situations [47].

Since the introduction of the German national structured and certified patient education program in November 2014 the num- ber of centers employing this structured program has been steadily growing in Germany ( $\mathbf{F i g}$. 1). By the end of 20181365 group education sessions for $2907 \mathrm{Al}$ patients were given in addition to 770 individual education sessions.

First evaluations of the program revealed a significant and lasting gain in knowledge on $\mathrm{Al}$ in general and on the prevention and management of AC [48]. Patients furthermore felt encouraged to manage emergency situations [48]. Whereas only $84 \%$ of participants were equipped with an emergency card and $49 \%$ possessed an emergency kit before participation in the program, all participants received both card and prescription of glucocorticoids for emergency use. Detailed results on the evaluation of the program will be published elsewhere. In a recent prospective analysis of the emergency management in 150 German patients with $\mathrm{Al}, 32 \%$ reported that they had performed self-injection and further $15 \%$ of patients reported glucocorticoid injection by a family member [37]. Of these study participants, $71 \%$ had participated in the standardized patient education program. In contrast, only $6 \%$ of respondents from the 2003 survey of the British Addison's disease self-helping group reported management of adrenal emergency by gluco- 
corticoid self-injection [40]. First preliminary evaluations of the patient education program among patients with secondary $\mathrm{Al}$ in our center in Berlin (23 women, 21 men; median age $60.5 \mathrm{yrs}$, range 18-83 yrs; median duration of disease 5 yrs, range $0-40$ yrs) showed that the patient's knowledge significantly increased after patient education and remained reasonably stable after 6-9 months. Furthermore, patients rated their general information status on $\mathrm{Al}$ as significantly improved $(\mathrm{p}<0.001)$ after the standardized education ( $>$ Fig. 2 ). In addition, more patients $(52.3 \%$ vs. $72.7 \%, p=0.154$ ) stated that they would dare to perform a self-injection after participation in the standardized education compared to before education ( $\triangleright$ Fig. $\mathbf{3}$ ).

Another recent study investigated the effect of providing information regarding $\mathrm{Al}, \mathrm{AC}$ and its management to 77 parents of children with congenital adrenal hyperplasia (CAH) [49]. They described a significant, positive relationship between detailed instruction to parents on AC management and perceived management ability [49]. This resulted in the observation that the stronger the perceived management ability was, the less impact the children's diagnosis of CAH had on the family [49].

Recently it was shown that longitudinal scores of the disease specific-QoL questionnaire AddiQoL and self-reporting of pre-crises via patient diaries are additional clinical tools to identify higher risks for critical events [50]. We think that those methods for selfevaluation towards early detection of clinical symptoms, also including glucose profiles on CGM devices in diabetic patients with $\mathrm{Al}$, will enable patients to adjust their glucocorticoid medication in special situations and thereby to regain independence and to take care of themselves.

However, the established educational programs are suited to the well-informed, cooperative and compliant patient. Several patients experience social decline during the disorder, are lost to follow-up and not reached by caregivers. This needs to be addressed in future programs. Furthermore, due to the fact that iatrogenic Al is often overlooked, patients on immuno-suppressive, or -modulatory glucocorticoid dosages may suffer morbidity and even die prematurely [8]. Such patients are not yet routinely identified and included in educational programs.

In summary, the current literature showed a significant gain of knowledge on Al in general, an increased understanding for dose adaptation in situations of intercurrent illness, and a higher selfconfidence to perform a self-injection of hydrocortisone after participation in a patient education program.

\section{Al Management and education during COVID-19}

Because lockdown and quarantine situations might occur, it is important that Al patients have enough supply of glucocorticoid tablets and their emergency set updated. The educated Al patient doubles or triples the daily hydrocortisone dose to approximately 40-50 mg/day in case of infectious diseases with fever. In the case of illness immediate release, regular oral hydrocortisone should be preferred over modified release hydrocortisone preparations [51]. As it relates to COVID-19, any patient with a dry continuous cough or mild fever should immediately double their daily oral glucocorticoid dose and continue on this regimen until the fever or the

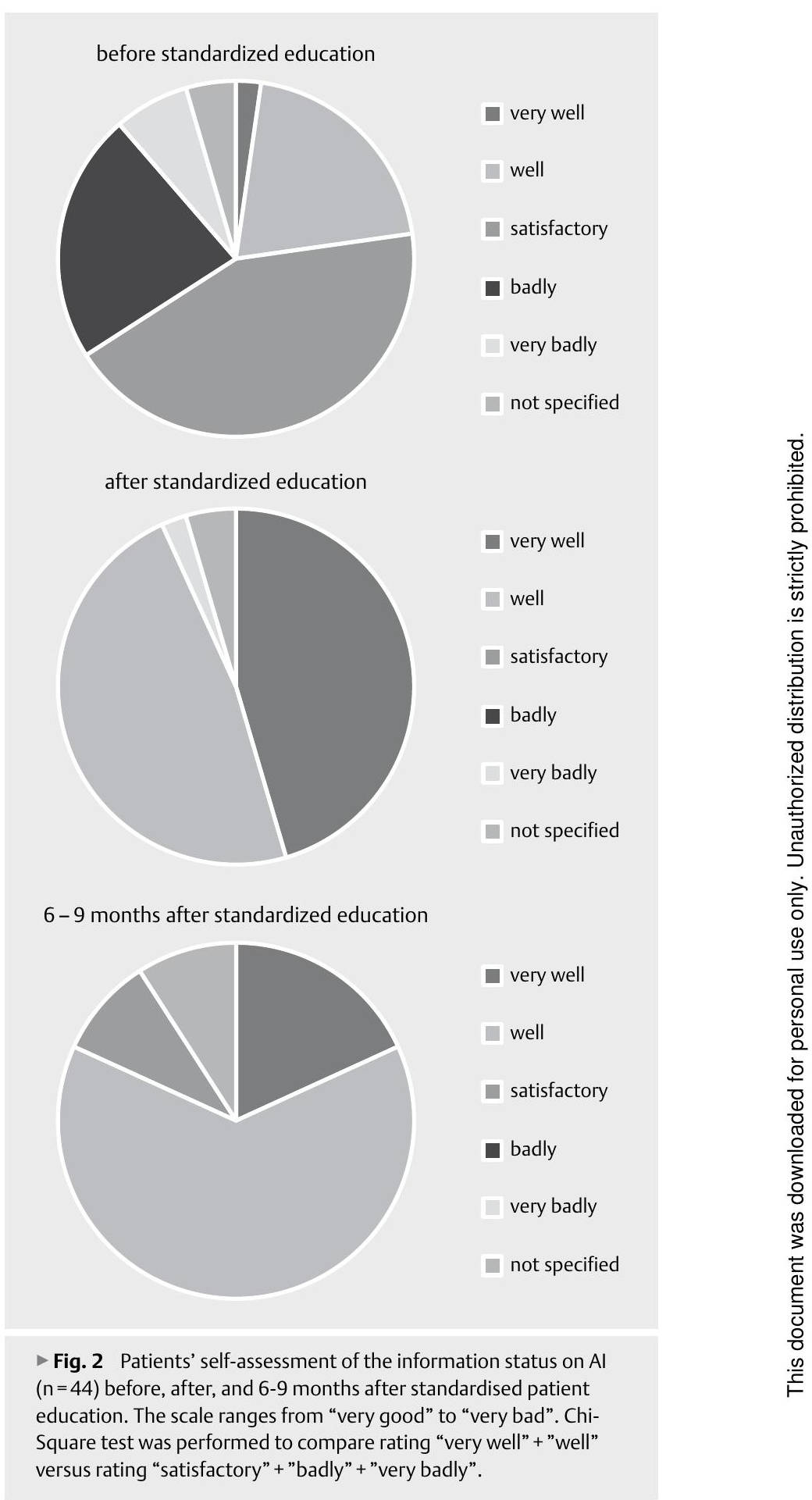

cough has subsided [52, 53]. Other authors suggest that an acute COVID-19 infection is associated with significant and persistent acute inflammation and often continuous high fever, which probably requires a more evenly spaced glucocorticoid cover throughout day and night (20 mg oral hydrocortisone every $6 \mathrm{~h}$ ) [51]. An Italian article suggests in the case of suspected pneumonia (fever $>38^{\circ} \mathrm{C}$ and signs of lower respiratory tract symptoms (persistent cough, respiratory rate $>30$ breaths/min, severe respirato- 

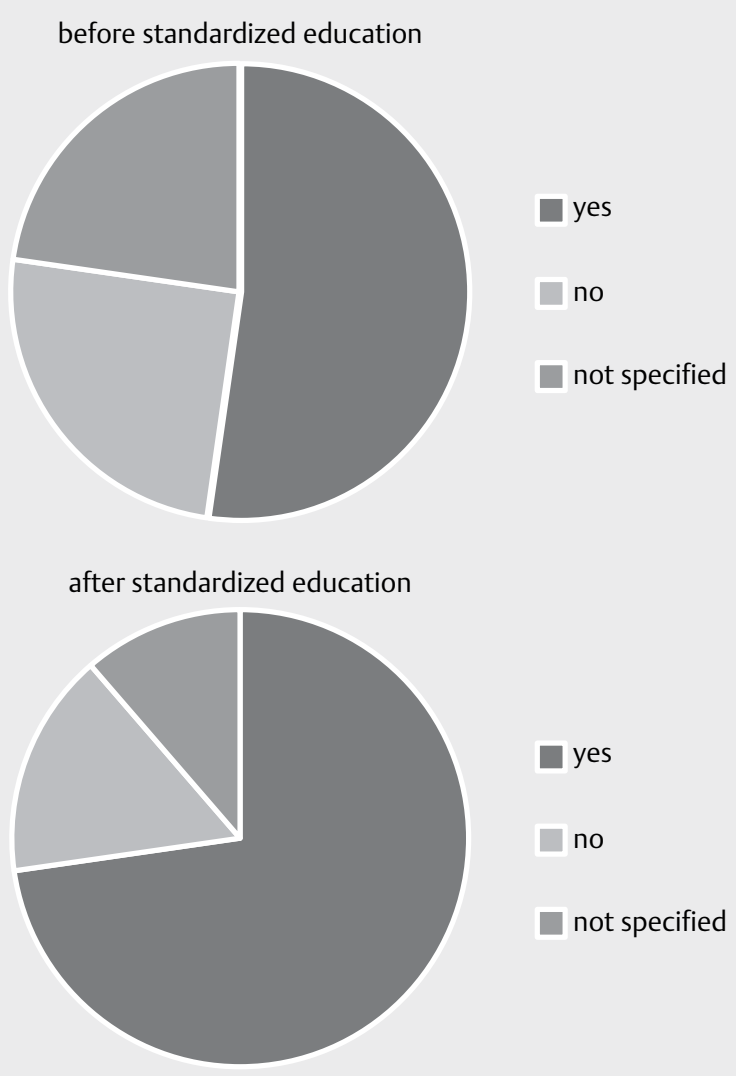

6-9 months after standardized education

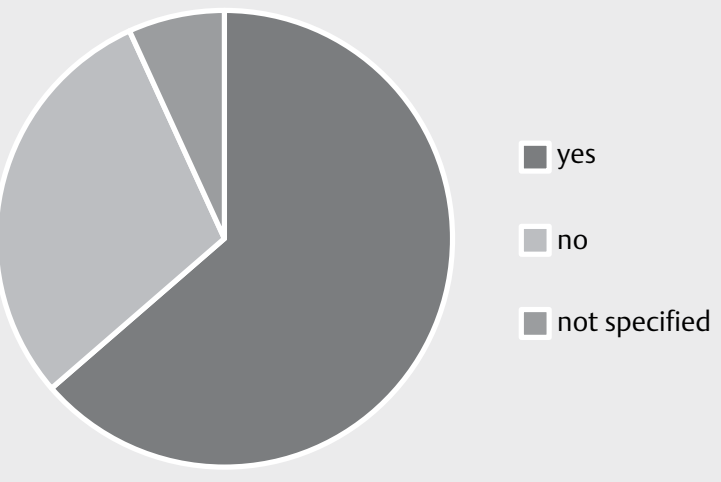

- Fig. 3 Percentage of patients with secondary Al $(n=44)$ who would dare to perform a self-injection before, directly after, and 6-9 months after patient education. Chi-Square test was performed to compare percentage of self-injection.

ry distress, $\mathrm{SpO}_{2} 93 \%$ on room air, hypotension) a hospitalization should be advised and hydrocortisone dose increased to $100 \mathrm{mg} /$ day [53]. Contrary to the general population, the threshold for hospitalization should be low for worsening symptoms in Al patients, considering their risk for an AC [53].

Deteriorating patients and those who experience vomiting or diarrhea should seek urgent medical care, use their emergency set (100 mg hydrocortisone i.m.) and be treated with parenteral phys- iological stress doses of hydrocortisone (50-100 mg intravenously t.i.d.) in the clinic [52].

The standardized patient education program cannot be organized as a personal meeting during a complete lockdown situation experienced recently in several countries due to the COVID-19 pandemic. Under such circumstances the patient education program should be transferred to an interactive online meeting using webconference and electronic meeting systems (e.g. ZOOM, Skype). However, the personal and direct learning of the hydrocortisone emergency self-injection is not possible. Under a partial lockdown situation which allows small group meetings (3-5 persons), the patient education program could be organized with precaution measures such as obligatory wearing of face masks of all participants, $2 \mathrm{~m}$ distance between the participants and with a good room ventilation. In addition, the session time should be restricted to $45 \mathrm{~min}$ with inclusion of the most important part of the education program: learning of the emergency hydrocortisone self-injection. The remaining 60-90 min teaching could be transferred to an interactive online meeting as mentioned above. The patient education program should be amended with guidance regarding stringent social distancing rules [51], use and handling of face masks, correct handwashing etc, because only these behavioral measures can prevent a primary SARS-COV2 exposure. Recently, UK/Swiss sociologists provided a mathematical model to illustrate, how strategies for reducing and selecting social contacts (limiting interaction to a few repeated contacts akin to forming social bubbles; seeking similarity across contacts; and strengthening communities via triadic strategies) will be efficient and can avoid complete isolation [54].

Furthermore, online platforms providing qualified Al patient information, such as Addison's self help group (https://www.addisonsdisease.org.uk) and Adrenal.eu (https://adrenals.eu) should be integrated into the patient education program.

\section{Conclusions}

Medical therapy of Al requires an educated patient who has a good knowledge of the disease, understands his medical therapy and is able to perform situational dose adaptation. Patient education and teaching has the potential to improve patient care, help to reduce the frequency as well as mortality of AC. It also improves self-assurance and subjective well-being of patients with Al. It should be stressed that patient education is part of the endocrinologist's therapeutic responsibility. The national structured and certified patient education program proves to be a good tool to improve management of patients with Al.

\section{Acknowledgements}

We thank the endocrine teams of the eight founding endocrine centers, their doctors and endocrine nurses: Würzburg (Stefanie Hahner, Stephanie Burger-Stritt, Walter Rüger, Silke Horn), BerlinCharlottenburg (Britta Bauer, Marcus Quinkler), Berlin-Charité (Tina Kienitz, Kathrin Zopf, Janina Sauerwald), Munich (Nicole Reisch), Frankfurt/M (Gesine Meyer, Maria Sandler, Maike Koch), Oldenburg (Michael Droste, Smadar Pahl, Jessica Norkeweit), Düsseldorf/Rostock (Holger Willenberg), Lübeck (Johannes Klein). The 
standardized teaching program is supported and owned by the Section "Nebenniere, Steroide, Hypertonie" and by the "Akademie für Fort- und Weiterbildung" of the German Endocrine Society (DGE, Deutsche Gesellschaft für Endokrinologie).

\section{Declaration of Interest}

The authors declare that they have no conflict of interest.

\section{References}

[1] Erichsen MM, Lovas K, Skinningsrud B et al. Clinical, immunological, and genetic features of autoimmune primary adrenal insufficiency: observations from a Norwegian registry. J Clin Endocrinol Metab 2009; 94: 4882-90. Epub 2009/10/28. doi: 10.1210/jc.2009-1368. PubMed PMID: 19858318

[2] Burman P, Mattsson AF, Johannsson G et al. Deaths among adult patients with hypopituitarism: hypocortisolism during acute stress, and de novo malignant brain tumors contribute to an increased mortality. J Clin Endocrinol Metab 2013; 98: 1466-75. Epub 2013/03/05. doi: 10.1210/jc.2012-4059. PubMed PMID: 23457412

[3] Sherlock M, Ayuk J, Tomlinson JW et al. Mortality in patients with pituitary disease. Endocr Rev. 2010; 31: 301-42. Epub 2010/01/21. doi: 10.1210/er.2009-0033. PubMed PMID: 20086217

[4] Bensing S, Brandt L, Tabaroj F et al. Increased death risk and altered cancer incidence pattern in patients with isolated or combined autoimmune primary adrenocortical insufficiency. Clin Endocrinol (Oxf) 2008; 69: 697-704. Epub 2008/08/30. doi: 10.1111/j.1365-2265.2008.03340.x. PubMed PMID: 18727712

[5] Falhammar H, Frisen L, Norrby $C$ et al. Increased mortality in patients with congenital adrenal hyperplasia due to 21-hydroxylase deficiency. J Clin Endocrinol Metab 2014; 99: E2715-21. Epub 2014/10/04. doi: 10.1210/jc.2014-2957. PubMed PMID: 25279502

[6] Bergthorsdottir R, Leonsson-Zachrisson M, Oden A et al. Premature mortality in patients with Addison's disease: a population-based study. J Clin Endocrinol Metab 2006; 91: 4849-53. Epub 2006/09/14. doi: 10.1210/jc.2006-0076. PubMed PMID: 16968806

[7] Smans LC, Souverein PC, Leufkens HG et al. Increased use of antimicrobial agents and hospital admission for infections in patients with primary adrenal insufficiency: a cohort study. Eur ] Endocrinol 2013; 168: 609-14. Epub 2013/02/07. doi: 10.1530/eje-12-0879. PubMed PMID: 23384710

[8] Mebrahtu TF, Morgan AW, Keeley A et al. Dose dependency of iatrogenic glucocorticoid excess and adrenal insufficiency and mortality: a cohort study in England. J Clin Endocrinol Metab 2019; Epub 2019/04/23. doi: 10.1210/jc.2019-00153. PubMed PMID: 31009052; PubMed Central PMCID: PMCPMC6656418

[9] Sherlock M, Reulen RC, Alonso AA et al. ACTH deficiency, higher doses of hydrocortisone replacement, and radiotherapy are independent predictors of mortality in patients with acromegaly. J Clin Endocrinol Metab 2009; 94: 4216-23. Epub 2009/10/08. doi: 10.1210/ jc.2009-1097. PubMed PMID: 19808848

[10] Zueger T, Kirchner P, Herren C et al. Glucocorticoid replacement and mortality in patients with nonfunctioning pituitary adenoma. J Clin Endocrinol Metab 2012; 97: E1938-42. Epub 2012/08/09. doi: 10.1210/jc.2012-2432. PubMed PMID: 22872686

[11] Rosen T, Bengtsson BA. Premature mortality due to cardiovascular disease in hypopituitarism. Lancet. 1990; 336: 285-8. Epub 1990/08/04. doi: 10.1016/0140-6736(90)91812-o. PubMed PMID: 1973979
[12] Clayton RN, Jones PW, Reulen RC et al. Mortality in patients with Cushing's disease more than 10 years after remission: a multicentre, multinational, retrospective cohort study. Lancet Diabetes Endocrinol. 2016; 4(7):569-76. Epub 2016/06/07. doi: 10.1016/s22138587(16)30005-5. PubMed PMID: 27265184

[13] Quinkler M, Ekman B, Zhang P et al. Mortality data from the European Adrenal Insufficiency Registry-Patient characterization and associations. Clin Endocrinol (Oxf) 2018; 89: 30-5. Epub 2018/04/24. doi: 10.1111/cen.13609. PubMed PMID: 29682773

[14] Behan LA, Carmody D, Rogers B et al. Low-dose hydrocortisone replacement is associated with improved arterial stiffness index and blood pressure dynamics in severely adrenocorticotrophin-deficient hypopituitary male patients. Eur J Endocrinol 2016; 174: 791-9. Epub 2016/03/31. doi: 10.1530/eje-15-1187. PubMed PMID: 27025241

[15] Werumeus Buning J, van Faassen M, Brummelman P et al. Effects of Hydrocortisone on the Regulation of Blood Pressure: Results From a Randomized Controlled Trial. J Clin Endocrinol Metab 2016; 101: 3691-9. Epub 2016/08/05. doi: 10.1210/jc.2016-2216. PubMed PMID: 27490921

[16] Allolio B, Lang K, Hahner S. Addisonian crisis in a young man with atypical anorexia nervosa. Nat Rev Endocrinol 2011; 7: 115-21. Epub 2010/12/24. doi: 10.1038/nrendo.2010.211. PubMed PMID: 21178996

[17] White K, Arlt W. Adrenal crisis in treated Addison's disease: a predictable but under-managed event. Eur J Endocrinol 2010; 162: 115-20. Epub 2009/09/25. doi: 10.1530/eje-09-0559. PubMed PMID: 19776201

[18] Hahner S, Loeffler M, Bleicken B et al. Epidemiology of adrenal crisis in chronic adrenal insufficiency: the need for new prevention strategies. Eur J Endocrinol 2010; 162: 597-602. Epub 2009/12/04. doi: 10.1530/ eje-09-0884. PubMed PMID: 19955259

[19] Omori K, Nomura K, Shimizu S et al. Risk factors for adrenal crisis in patients with adrenal insufficiency. Endocr J. 2003; 50: 745-52. Epub 2004/01/08. doi: 10.1507/endocrj.50.745. PubMed PMID: 14709847

Reisch N, Willige M, Kohn D et al. Frequency and causes of adrenal crises over lifetime in patients with 21-hydroxylase deficiency. Eur J Endocrinol 2012; 167: 35-42. Epub 2012/04/20. doi: 10.1530/ eje-12-0161. PubMed PMID: 22513882

[20] Allolio B. Extensive expertise in endocrinology. Adrenal crisis. Eur ] Endocrinol 2015; 172: R115-24. Epub 2014/10/08. doi: 10.1530/ eje-14-0824. PubMed PMID: 25288693

[21] Hahner S, Spinnler C, Fassnacht M et al. High incidence of adrenal crisis in educated patients with chronic adrenal insufficiency: a prospective study. | Clin Endocrinol Metab 2015; 100: 407-16. Epub 2014/11/25 doi: 10.1210/jc.2014-3191. PubMed PMID: 25419882

[22] Husebye ES, Allolio B, Arlt W et al. Consensus statement on the diagnosis, treatment and follow-up of patients with primary adrenal insufficiency. J Intern Med 2014; 275: 104-15. Epub 2013/12/18. doi: 10.1111/joim.12162. PubMed PMID: 24330030

[23] Grossman A, Johannsson G, Quinkler M et al. Therapy of endocrine disease: Perspectives on the management of adrenal insufficiency: clinical insights from across Europe. Eur J Endocrinol 2013; 169: R165-75. Epub 2013/09/14. doi: 10.1530/eje-13-0450. PubMed PMID: 24031090; PubMed Central PMCID: PMCPMC3805018

[24] Murray RD, Ekman B, Uddin S et al. Management of glucocorticoid replacement in adrenal insufficiency shows notable heterogeneity data from the EU-AIR. Clin Endocrinol (Oxf) 2017; 86: 340-6 .Epub 2016/11/02. doi: 10.1111/cen.13267. PubMed PMID: 27801983

[25] Bornstein SR, Allolio B, Arlt W et al. Diagnosis and Treatment of Primary Adrenal Insufficiency: An Endocrine Society Clinical Practice Guideline. J Clin Endocrinol Metab 2016; 101: 364-89. Epub 2016/01/14. doi: 10.1210/jc.2015-1710. PubMed PMID: 26760044 PubMed Central PMCID: PMCPMC4880116 
[26] Esteban NV, Loughlin T, Yergey AL et al. Daily cortisol production rate in man determined by stable isotope dilution/mass spectrometry. J Clin Endocrinol Metab 1991; 72: 39-45. Epub 1991/01/01. doi: 10.1210/jcem-72-1-39. PubMed PMID: 1986026

[27] Mah PM, Jenkins RC, Rostami-Hodjegan A et al. Weight-related dosing, timing and monitoring hydrocortisone replacement therapy in patients with adrenal insufficiency. Clin Endocrinol (Oxf) 2004; 61: 367-75. Epub 2004/09/10. doi: 10.1111/j.1365-2265.2004.02106.x. PubMed PMID: 15355454

[28] Weise M, Drinkard B, Mehlinger SL et al. Stress dose of hydrocortisone is not beneficial in patients with classic congenital adrenal hyperplasia undergoing short-term, high-intensity exercise. J Clin Endocrinol Metab 2004; 89: 3679-84. Epub 2004/08/05. doi: 10.1210/ jc.2003-032051 PubMed PMID: 15292287

[29] Simunkova K, Jovanovic N, Rostrup E et al. Effect of a pre-exercise hydrocortisone dose on short-term physical performance in female patients with primary adrenal failure. Eur J Endocrinol 2016; 174: 97-105.. Epub 2015/10/24. doi: 10.1530/eje-15-0630. PubMed PMID: 26494876

[30] Quinkler M, Hahner S. What is the best long-term management strategy for patients with primary adrenal insufficiency? Clin Endocrinol (Oxf) 2012; 76: 21-5. Epub 2011/05/19. doi: 10.1111/j.1365-2265.2011.04103.x. PubMed PMID: 21585418

[31] Quinkler M, Beuschlein F, Hahner $S$ et al. Adrenal cortical insufficiency-a life threatening illness with multiple etiologies. Dtsch Arztebl Int 2013; 110: (51-52) 882-8 Epub 2014/02/18. doi: 10.3238/arztebl.2013.0882. PubMed PMID: 24529304; PubMed Central PMCID: PMCPMC3928535

[32] Quinkler M, Hahner S, Johannsson G et al. Saving lives of patients with adrenal insufficiency: a pan-European initiative? Clin Endocrinol (Oxf) 2014; 80: 319-21. Epub 2013/12/05. doi: 10.1111/cen.12378. PubMed PMID: 24299429

[33] Quinkler M, Dahlqvist P, Husebye ES et al. A European Emergency Card for adrenal insufficiency can save lives. Eur I Intern Med 2015; 26: 75-6. Epub 2014/12/17. doi: 10.1016/j.ejim.2014.11.006. PubMed PMID: 25498511

[34] Petersenn S, Honegger J, Quinkler M. National German Audit of Diagnosis, Treatment, and Teaching in Secondary Adrenal Insufficiency. Horm Metab Res 2017; 49: 580-8. Epub 2017/03/30. doi: 10.1055/s-0043-105077. PubMed PMID: 28351092

[35] Hahner S, Hemmelmann N, Quinkler M et al. Timelines in the management of adrenal crisis - targets, limits and reality. Clin Endocrinol (Oxf) 2015; 82: 497-502. Epub 2014/09/10. doi: 10.1111/ cen.12609 PubMed PMID: 25200922

[36] Burger-Stritt S, Kardonski P, Pulzer A et al. Management of adrenal emergencies in educated patients with adrenal insufficiency-A prospective study. Clin Endocrinol (Oxf) 2018; 89: 22-9. Epub 2018/04/05. doi: 10.1111/cen.13608. PubMed PMID: 29617051

[37] Kampmeyer D, Lehnert $\mathrm{H}$, Moenig $\mathrm{H}$ et al. Experience pays off! Endocrine centres are essential in the care of patients with adrenal insufficiency. Eur J Intern Med 2016; 35: e27-e28. Epub 2016/07/23. doi: 10.1016/j.ejim.2016.07.008. PubMed PMID: 27444736

[38] Harbeck B, Brede S, Witt C et al. Glucocorticoid replacement therapy in adrenal insufficiency--a challenge to physicians? Endocr J. 2015; 62: 463-8 Epub 2015/03/06. doi: 10.1507/endocrj.Ej14-0612. PubMed PMID: 25739727

[39] White KG. A retrospective analysis of adrenal crisis in steroid-dependent patients: causes, frequency and outcomes. BMC Endocr Disord 2019; 19: 129. Epub 2019/12/04. doi: 10.1186/s12902-019-0459-z PubMed PMID: 31791297; PubMed Central PMCID: PMCPMC6889201
[40] Forss M, Batcheller G, Skrtic S et al. Current practice of glucocorticoid replacement therapy and patient-perceived health outcomes in adrenal insufficiency - a worldwide patient survey. BMC Endocr Disord 2012; 12: 8. Epub 2012/06/15. doi: 10.1186/1472-6823-12-8. PubMed PMID: 22695167; PubMed Central PMCID: PMCPMC3403959

[41] Tiemensma J, Andela CD, Pereira AM et al. Patients with adrenal insufficiency hate their medication: concerns and stronger beliefs about the necessity of hydrocortisone intake are associated with more negative illness perceptions. J Clin Endocrinol Metab 2014; 99 : 3668-76. Epub 2014/09/17. doi: 10.1210/jc.2014-1527. PubMed PMID: 25226291

[42] Chapman SC, Llahana S, Carroll P et al. Glucocorticoid therapy for adrenal insufficiency: nonadherence, concerns and dissatisfaction with information. Clin Endocrinol (Oxf) 2016; 84: 664-71. Epub 2015/12/08. doi: 10.1111/cen.12991. PubMed PMID: 26641418

[43] Schofl C, Mayr B, Maison N et al. Daily adjustment of glucocorticoids by patients with adrenal insufficiency. Clin Endocrinol (Oxf) 2019; 91: 256-62. Epub 2019/05/06. doi: 10.1111/cen.14004. PubMed PMID: 31050815

[44] Guignat L. Therapeutic patient education in adrenal insufficiency. Ann Endocrinol (Paris) 2018; 79: 167-73. Epub 2018/04/03. doi: 10.1016/j. ando.2018.03.002. PubMed PMID: 29606279

[45] Burger-Stritt S, Hahner S. [Adrenal Insufficiency]. Dtsch Med Wochenschr 2016; 141: 1740-2. Epub 2016/12/03. doi: 10.1055/s-0042-118276. PubMed PMID: 27903023

[46] Repping-Wuts HJ, Stikkelbroeck NM, Noordzij A et al. A glucocorticoid education group meeting: an effective strategy for improving self-management to prevent adrenal crisis. Eur J Endocrinol 2013; 169: 17-22. Epub 2013/05/03. doi: 10.1530/eje-12-1094. PubMed PMID: 23636446

[47] Eff A, Burger-Stritt S, Quinkler M. Evaluation of a German-wide Education Programme For Patients With Adrenal Insufficiency - First Interim Analysis. Poster, DACH-Tagung München 2016; P01-P13

[48] Fleming L, Knafl K, Knafl G et al. Parental management of adrenal crisis in children with congenital adrenal hyperplasia. J Spec Pediatr Nurs 2017; 22: 4. Epub 2017/08/05. doi: 10.1111/jspn.12190. PubMed PMID: 28771930; PubMed Central PMCID: PMCPMC5884098

[49] Meyer G, Koch M, Herrmann E et al. Longitudinal AddiQoL scores may identify higher risk for adrenal crises in Addison's disease. Endocrine 2018; 60: 355-61. Epub 2018/02/02. doi: 10.1007/s12020-017-1513-0. PubMed PMID: 29388043

[50] Arlt W, Baldeweg SE, Pearce SHS et al. Endocrinology in the time of COVID-19: Management of adrenal insufficiency. Eur J Endocrinol. 2020; Epub 2020/05/08. doi: 10.1530/eje-20-0361 PubMed PMID: 32379699

[51] Kaiser UB, Mirmira RG, Stewart PM. Our Response to COVID-19 as Endocrinologists and Diabetologists. J Clin Endocrinol Metab 2020; 105: 5. Epub 2020/04/02. doi: 10.1210/clinem/dgaa148. PubMed PMID: 32232480; PubMed Central PMCID: PMCPMC7108679

[52] Isidori AM, Pofi R, Hasenmajer V et al. Use of glucocorticoids in patients with adrenal insufficiency and COVID-19 infection. Lancet Diabetes Endocrinol. 2020; Epub 2020/04/27. doi: 10.1016/s22138587(20)30149-2. PubMed PMID: 32334645; PubMed Central PMCID: PMCPMC7180011

[53] Block P, Hoffman M, Raabe IJ et al. Social Network-Based Distancing Strategies to Flatten the COVID-19 Curve in a Post-Lockdown World. Nat Hum Behav 2020; 4: 588-596. doi: 10.1038/s41562-020-0898-6. Epub 2020 Jun 4 